\title{
Mild steel corrosion inhibition by aqueous extract of Hyptis Suaveolens leaves
}

\author{
P. Muthukrishnan • B. Jeyaprabha • \\ P. Prakash
}

Received: 23 October 2012/ Accepted: 19 December 2013/Published online: 20 February 2014

(C) The Author(s) 2014. This article is published with open access at Springerlink.com

\begin{abstract}
Hyptis suaveolens leaf extract (HSLE) as corrosion inhibitor in $1 \mathrm{M} \mathrm{H}_{2} \mathrm{SO}_{4}$ was evaluated using mass loss measurement as well as potentiodynamic polarization and electrochemical impedance spectroscopy measurements. The extract was found to efficiently inhibit the corrosion process in $1 \mathrm{M} \mathrm{H}_{2} \mathrm{SO}_{4}$ and inhibition efficiency increased with increasing extract concentration. Maximum inhibition efficiency of HSLE in $1 \mathrm{M}$ $\mathrm{H}_{2} \mathrm{SO}_{4}$ was found to be $95 \%$. The potentiodynamic polarization results revealed that HSLE acted as mixedtype inhibitor. The adsorption of the studied inhibitor on mild steel obeyed Langmuir adsorption isotherm. The nature of protective film formed on the surface of the mild steel was confirmed by FT-IR, XRD and SEM techniques. This study clearly shows the efficiency of HSLE for control of mild steel corrosion in $1 \mathrm{M} \mathrm{H}_{2} \mathrm{SO}_{4}$ solutions.
\end{abstract}

Keywords Mild steel · Corrosion inhibition - Hyptis suaveolens $\cdot$ XRD $\cdot$ Polarization $\cdot$ SEM

P. Muthukrishnan · P. Prakash ( $₫)$

Department of Chemistry, Thiagarajar College,

Madurai 625009, Tamilnadu, India

e-mail: kmpprakash@gmail.com

P. Muthukrishnan

e-mail: mukepmk@gmail.com

B. Jeyaprabha

Department of Civil Engineering, Fatima Michael College of

Engineering and Technology, Madurai 625020, Tamilnadu, India

e-mail: jeyaprabha@gmail.com

\section{Introduction}

Mild steel is a familiar material employed widely in a variety of industries. But the main problem of using mild steel is its dissolution in acidic solutions. In various industrial processes, acid solutions are commonly used for removal of rust and scale. Use of inhibitors in these processes to prevent metal dissolution is very common [1-3]. Most of the well-known acid inhibitors are organic compounds containing nitrogen, sulfur, oxygen, heterocyclic compounds with a polar functional group and conjugated double bond [4-7]. These compounds are adsorbed on the metallic surface and block the active corrosion sites [8]. Most of the synthetic chemicals are costly, toxic to both human being and the environment. To solve the above defects, it is necessary to develop cheap, non-toxic and environmentally friendly natural products as corrosion inhibitors. These natural organic compounds are either synthesized or extracted from aromatic herbs, spices and medicinal plants. Plant extracts are an incredibly rich source of naturally synthesized chemical compounds that can be extracted by simple procedures with low cost and are biodegradable in nature. The use of these natural compounds extracted from leaves or seeds as corrosion inhibitors have been reported by several authors [9-16]. Subramania et al. [17] studied the corrosion inhibition of leaf extracts of curry leaves, henna leaves as well as extracts from seeds of Jack fruit and tamarind on mild steel corrosion in acidic solutions. Other than the plant extracts, pure organic compounds extracted from natural products such as piperine [18], Ellagic acid, tannic acid [19], tryptamine [20], caffeine [21], Pennyroyal oil [22], amino acids [23] and caffeic acid [24] have also been used for inhibition of corrosion. Hyptis suaveolens is easily available in India. It is a medium-sized forest tree which has 
$2 \mathrm{~m}$ height and belongs to Lamiaceae family. It is commonly known as Wilayati tulasi. It is also used for parasitical cutaneous diseases, infection of uterus, and as sudorific in catarrhal condition, skin disease, headache, stomachache and snuff to stop bleeding of the nose. The extract of this plant contains numerous naturally environmental organic compounds. The genus of $H$. suaveolens is known to contain significant amount of volatile oils, starch, protein, tannins, saponins, alkaloids, flavonoids and glycosides $[25,26]$. The leaf of the plant is biodegradable and a renewable material.

The aim of this study was to investigate the corrosion of mild steel in $1 \mathrm{M} \mathrm{H}_{2} \mathrm{SO}_{4}$ in the presence of $\mathrm{H}$. suaveolens leaf extract by mass loss, potentiodynamic polarization, electrochemical impedance, FT-IR, XRD and SEM. In addition, thermodynamic and kinetic data were evaluated.

\section{Experimental}

\section{Materials preparation}

Corrosion tests were performed on mild steel specimens with the composition of C-0.05, Mn-0.6, P-0.36, Si-0.03 and the remaining of $\mathrm{Fe}$. The specimens were mechanically cut into size of $2.5 \times 2.5 \times 0.4 \mathrm{~cm}$ dimensions and abraded with different emery papers up to $4 / 0$ grades. Then, they were washed with acetone, dried at room temperature and stored in moisture-free desiccator before corrosion tests.

\section{Preparation of Hyptis suaveolens leaf extract}

About $15 \mathrm{~g}$ of dried and powdered leaves of $H$. suaveolens was soaked in water and ethanol for 1 day. After 1 day, the plant extract was boiled, cooled and then triple filtered. Excess of ethanol was removed from vacuum distillation. The amount of plant material extracted into solution was quantified by comparing the weight of dried residue with initial weight of the dried plant material before extraction. The plant extract had a dark brown color. From the respective stock solutions, inhibitor test solutions were prepared in the concentration range $50-250 \mathrm{mg} \mathrm{l}^{-1}$.

\section{Methods}

\section{Mass loss method (ASTM standard)}

The polished and pre-weighed mild steel square specimens were immersed in $100 \mathrm{ml}$ test solution with $0-250 \mathrm{mg} \mathrm{l}^{-1}$ inhibitor, maintained at different temperatures in the range of $308-328 \mathrm{~K}$ for $48 \mathrm{~h}$. After $48 \mathrm{~h}$ immersion, the specimens were taken from solution, washed in double distilled water, dried and then weighed. The mass loss $(\Delta M)$ was used to calculate the corrosion rate $(\mathrm{CR})$ and the inhibition efficiency (IE),

$\mathrm{CR}(\mathrm{mpy})=534 \times \Delta M / D \times S \times T$

IE $\%=\left(M L_{0}-M L_{\mathrm{i}}\right) / M L_{0} \times 100$

Here $\Delta M=\left(M L_{0}-M L_{\mathrm{i}}\right)$, where $M L_{0}$ and $M L_{\mathrm{i}}$ are the mass loss of mild steel in the absence and presence of inhibitor, respectively, $D$ is the density of the iron $\left(\mathrm{g} \mathrm{cm}^{-3}\right), S$ is the area of the specimen in $i n \mathrm{ch}^{2}, T$ is the period of immersion in hours.

\section{Electrochemical measurements}

$\mathrm{CH}$ electrochemical analyzer Model 604D was used to record Tafel polarization curve and Nyquist impedance curve. The working electrode area of $0.5 \mathrm{~cm}^{2}$ mild steel specimen was exposed to the acid solution. Platinum and saturated calomel electrodes were used as counter electrode and reference electrode, respectively. All electrochemical measurements were carried out at $308 \mathrm{~K}$ using $100 \mathrm{ml}$ of electrolyte $\left(1 \mathrm{M} \mathrm{H}_{2} \mathrm{SO}_{4}\right)$ in stationary condition. Before each potentiodynamic polarization (Tafel) and electrochemical impedance spectroscopy (EIS) measurement, the electrode was immersed in test solution at open circuit potential (OCP) for $10 \mathrm{~min}$ to be sufficient to attain a stable state. Potentiodynamic polarization curves were recorded from -200 to $+200 \mathrm{mV}_{\mathrm{SCE}}$, (versus OCP) with a scan rate of $5 \mathrm{mV} \mathrm{s}^{-1}$. AC impedance spectra were recorded in the same instrument for polarization study using three-electrode cell assembly. The real part and imaginary part of the cell impedance were measured in ohms for various frequencies. The charge-transfer resistance $\left(R_{\mathrm{ct}}\right)$ and doublelayer capacitance $\left(C_{\mathrm{dl}}\right)$ values were calculated.

$R_{\mathrm{ct}}=\left(R_{\mathrm{s}}+R_{\mathrm{ct}}\right)-R_{\mathrm{s}}$

$C_{\mathrm{dl}}=1 / 2 \cdot \pi R_{\mathrm{ct}} f_{\max }$

where $R_{\mathrm{s}}=$ solution resistance, $f_{\max }=$ maximum frequency. AC impedance was recorded with initial $\mathrm{E}$ $(\mathrm{V})=\mathrm{OCP}$ values, high frequency $(\mathrm{Hz})=1 \times 10^{5}$, low frequency $(\mathrm{Hz})=0.1$; amplitude $(V)=0.005$ and quiet time $(s)=2$. Each experiment was run in triplicate to check the reproducibility of the data.

Surface analysis

Fourier transform infra red spectroscopy (FT-IR)

FT-IR spectra were recorded in SHIMADZU-FTIR-8400S spectrophotometer. One specimen for FT-IR characterization was the HSLE powder, which was mixed with $\mathrm{KBr}$ and made into the disk. On the other hand, the mild steel 
specimens were immersed for $12 \mathrm{~h}$ in $100 \mathrm{ml}$ of $1 \mathrm{M}$ $\mathrm{H}_{2} \mathrm{SO}_{4}$ solution containing $250 \mathrm{mg} \mathrm{l}^{-1}$ HSLE. After $12 \mathrm{~h}$, the specimens were taken out and dried and then rubbed with a small amount of $\mathrm{KBr}$ powder and made into the disk.

\section{$X$-ray diffraction and SEM characterizations}

The mild steel specimens were immersed in acid solutions in the absence and presence of optimum concentration of inhibitor for a period of $12 \mathrm{~h}$. After $12 \mathrm{~h}$, the specimens were taken out and dried. The nature of the surface film formed on the surface of the mild steel specimen was examined using X-ray diffractometer, Model (Phillips) X' pert and JEOL (JSM 6390) Scanning Electron Microscope.

\section{Results and discussion}

Mass loss measurements

Figure 1 shows the effect of concentration of HSLE on the corrosion rate and inhibition efficiency of mild steel exposed in uninhibited and inhibited acid solutions. From the graph, it is clear that the corrosion rate of mild steel decreased and the inhibition efficiency increased in the presence of inhibitor when compared to acid solution. The corrosion rate decreased on increasing HSLE concentration, which seems to point out simple adsorption behavior [27]. The maximum inhibition efficiency was found to be $76 \%$ at $250 \mathrm{mg}^{-1}(308 \mathrm{~K})$, which indicated that HSLE was a good inhibitor in $1 \mathrm{M} \mathrm{H}_{2} \mathrm{SO}_{4}$. Figure 2 shows that the inhibition efficiency decreased with increase of temperature, which was due to the gradual desorption of inhibitors from the surface of mild steel. It explains the lower inhibition efficiency at high temperature [28, 29]. Figure 3 shows the variation of corrosion rate with time for the corrosion of mild steel in $1 \mathrm{M} \mathrm{H}_{2} \mathrm{SO}_{4}$ containing various concentrations of HSLE. From the figure, it is evident that corrosion rate of mild steel increased with increase in the period of contact time but decreased with increase in the concentration of HSLE. It is obvious that the corrosion rate varied linearly with immersion period in uninhibited and inhibited acid, showing the unavailability of insoluble product on the mild steel surface. Shriver et al. [30] have explained that decrease in inhibition for long period of immersion can be attributed to the depletion of available inhibitor molecules in the solution due to complex formation between iron and the inhibitor molecules. Inhibition efficiency of HSLE against the immersion time is shown in Fig. 4. At higher temperature (313-328 K; plots not shown), corrosion rate of mild steel was found to increase

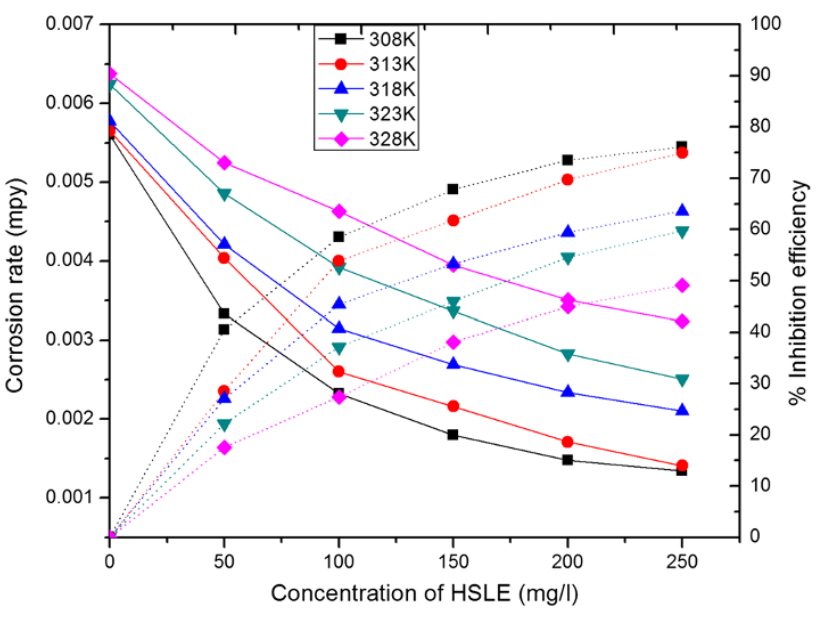

Fig. 1 Corrosion rate and inhibition efficiency of mild steel specimens immersed in $1 \mathrm{M} \mathrm{H}_{2} \mathrm{SO}_{4}$ with and without HSLE at 308, 313, 318, 323 and $328 \mathrm{~K}$; (dashed line) corrosion rate; (dotted line) inhibition efficiency

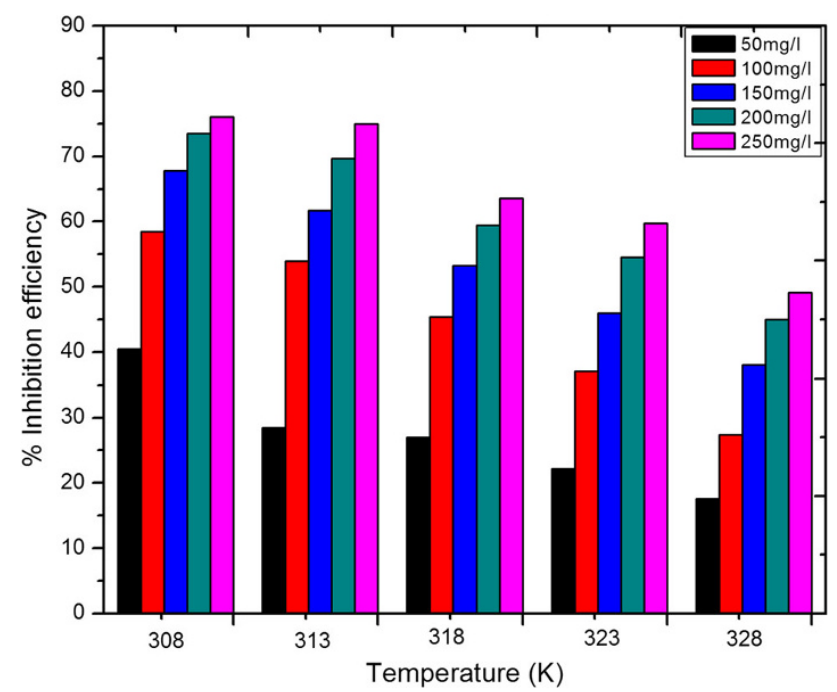

Fig. 2 Variation of inhibition efficiency with temperature at different concentrations

with increasing temperature indicating the desorption of adsorbed protective film at higher temperature.

Potentiodynamic polarization measurements

The polarization behavior of mild steel in $1 \mathrm{M} \mathrm{H}_{2} \mathrm{SO}_{4}$ solution in the presence and absence of HSLE is shown in Fig. 5. From the figure, it is clear that the anodic reactions of steel electrode corrosion were inhibited with the increasing HSLE concentrations. Also, the addition of HSLE has suppressed the cathodic reactions to lesser 


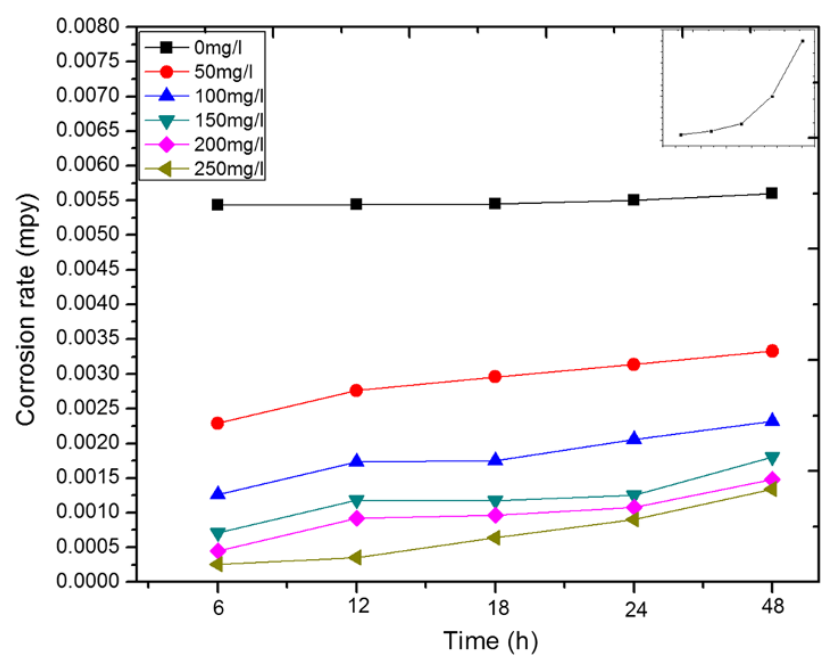

Fig. 3 Corrosion rate as a function of time in free acid (filled square) (inset) and with different concentrations of HSLE at $308 \mathrm{~K}$

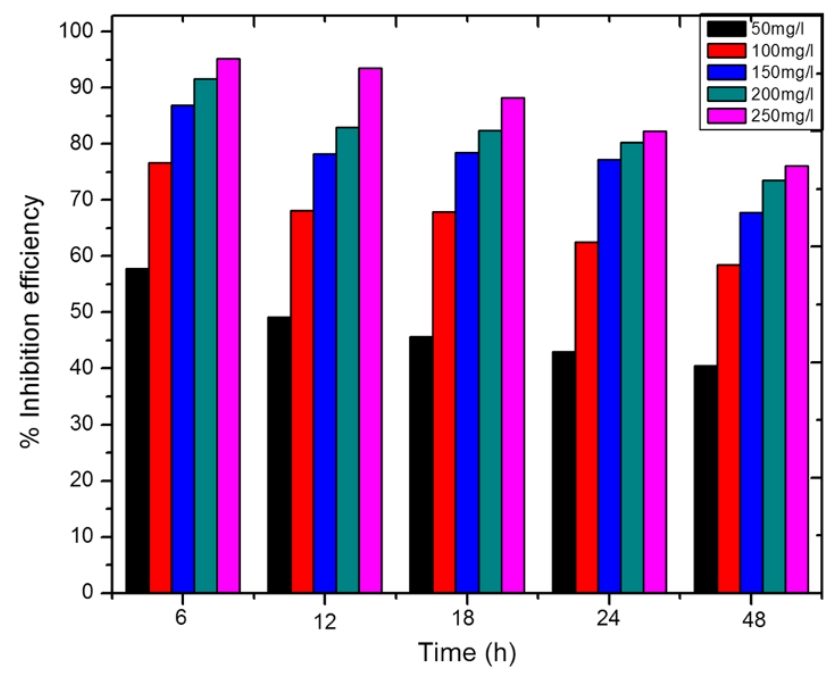

Fig. 4 Inhibition efficiency of HSLE as a function of time in $1 \mathrm{M}$ $\mathrm{H}_{2} \mathrm{SO}_{4}$ solution

extent than the anodic one. It means that the addition of HSLE reduced the anodic dissolution and retarded the hydrogen evolution reaction, which suggested that the inhibitor acts as mixed-type inhibitor [31-33]. The values of $b_{a}$ were shifted to higher values with reference to blank in the presence of HSLE. This shows that HSLE inhibited the corrosion mechanism by controlling anodic reactions predominantly and cathodic sites of the metal surface [34]. Electrochemical kinetic parameters such as corrosion potential $\left(E_{\text {corr }}\right)$, cathodic and anodic slope $\left(b_{\mathrm{c}}\right.$ and $\left.b_{\mathrm{a}}\right)$, corrosion current density $\left(i_{\text {corr }}\right)$ and percentage of inhibition efficiency were obtained from Tafel curves and are given in Table 1.

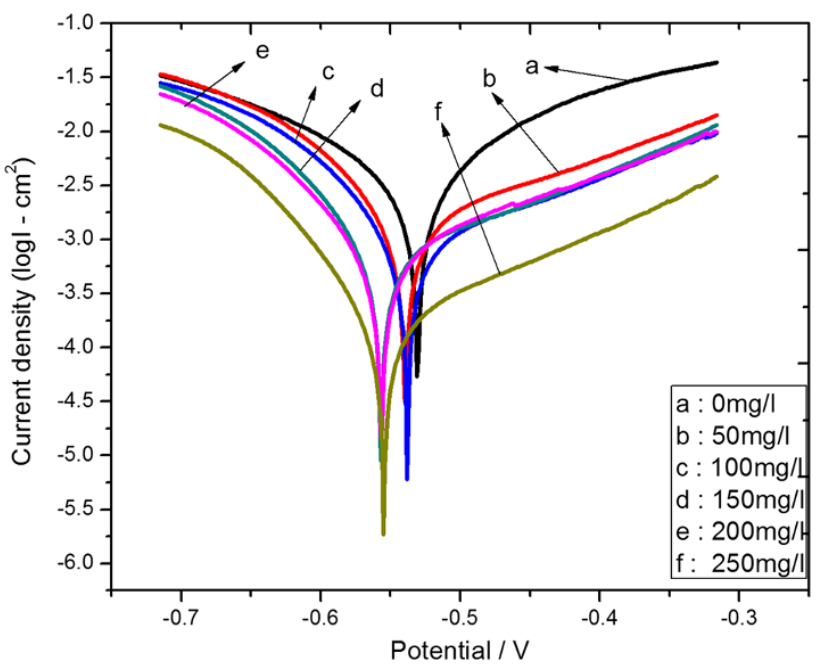

Fig. 5 Tafel plots of mild steel immersed in $1 \mathrm{M} \mathrm{H}_{2} \mathrm{SO}_{4}$ with and without HSLE

The inhibition efficiency is defined as

IE $\%=\left(i_{\text {corr }}^{0}-i_{\text {corr }} / i_{\text {corr }}^{0}\right) \times 100$

where $i_{\text {corr }}^{0}$ and $i_{\text {corr }}$ are the corrosion current density values in the absence and presence of inhibitor, respectively. Table 1 shows that the $i_{\text {corr }}$ values decreased in the presence of inhibitor than acid solution which was due to the increase in the blocked fraction of the electrode surface by adsorption.

\section{Electrochemical impedance spectroscopy}

Nyquist plots of mild steel obtained in $1 \mathrm{M} \mathrm{H}_{2} \mathrm{SO}_{4}$ solution in the absence and presence of various concentrations of HSLE are given in Fig. 6. This figure shows single depressed semicircle. This observation indicated that the corrosion of mild steel in $1 \mathrm{M} \mathrm{H}_{2} \mathrm{SO}_{4}$ solution was mainly controlled by a charge-transfer process. Although the appearance of Nyquist plots remained the same, their diameter increased after the addition of HSLE to the corrosive solution. This increase was more and more pronounced with increasing inhibitor concentration which indicated the adsorption of inhibitor molecules on the metal surface [35].

In the evaluation of Nyquist plots, the difference in real impedance at lower and higher frequencies is commonly considered as a charge-transfer resistance. Charge-transfer resistance $\left(R_{\mathrm{ct}}\right)$ values and double-layer capacitance values $\left(C_{\mathrm{dl}}\right)$ were obtained and are shown in Table 2. From the values, it could be seen that the charge-transfer resistance increased with increase in concentration of inhibitor in acid solution, which indicated the insulated adsorption layers formation. In the impedance studies, IE $\%$ is calculated as [36]: 
Table 1 Potentiodynamic polarization parameters for the corrosion of mild steel in $1 \mathrm{M}$ sulphuric acid containing different concentrations of HSLE

\begin{tabular}{lllllcl}
\hline $\begin{array}{l}C_{\text {inh }} \\
\left(\mathrm{mg} \mathrm{l}^{-1}\right)\end{array}$ & $\begin{array}{l}E_{\text {corr }} \\
(\mathrm{mV})\end{array}$ & $\begin{array}{l}i_{\text {corr }} \\
\left.(\mu \mathrm{A} \mathrm{cm})^{-2}\right)\end{array}$ & $\begin{array}{l}-b_{\mathrm{c}} \\
\left.(\mathrm{mV} \mathrm{decade})^{-1}\right)\end{array}$ & $\begin{array}{l}-b_{\mathrm{a}} \\
\left.(\mathrm{mV} \mathrm{decade})^{-1}\right)\end{array}$ & $\begin{array}{l}R_{\mathrm{p}} \\
\left(\Omega \mathrm{cm}^{2}\right)\end{array}$ & $\%$ IE \\
\hline 0 & -531 & 4,622 & 168.0 & 158.6 & 7.70 & - \\
50 & -528 & 2,362 & 244.4 & 129.1 & 15.6 & 48.9 \\
100 & -529 & 1,513 & 227.8 & 119.9 & 22.8 & 67.2 \\
150 & -532 & 1,191 & 221.6 & 108.9 & 26.7 & 74.2 \\
200 & -532 & 1,042 & 228.2 & 105.4 & 30.1 & 77.4 \\
250 & -534 & 229.3 & 189.5 & 83.43 & 109.9 & 95.0 \\
\hline
\end{tabular}

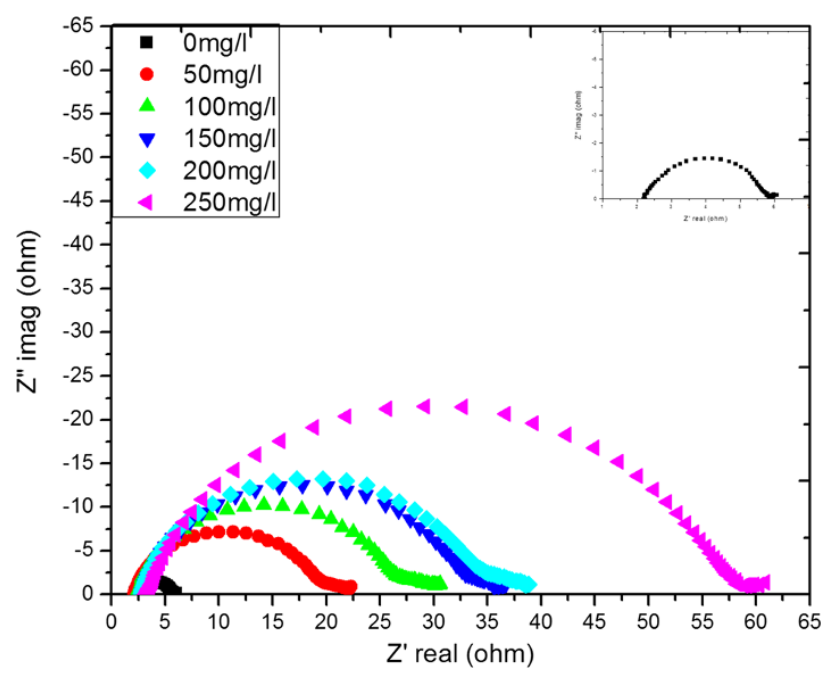

Fig. 6 Nyquist plots for mild steel immersed in $1 \mathrm{M} \mathrm{H}_{2} \mathrm{SO}_{4}$ (filled square) (inset) and with different concentration of HSLE at $308 \mathrm{~K}$

$\mathrm{IE} \%=\left(R_{\mathrm{ct}}-R_{\mathrm{ct}}^{0} / R_{\mathrm{ct}}\right) \times 100$

where $R_{\mathrm{ct}}^{0}$ and $R_{\mathrm{ct}}$ are uninhibited and inhibited chargetransfer resistance, respectively. It is clear from Table 2 that the $C_{\mathrm{dl}}$ values decreased and charge-transfer resistance increased after addition of inhibitor concentrations. The decrease in $C_{\mathrm{dl}}$ was due to the gradual replacement of water molecules by the adsorption of inhibitor molecules at metal/solution interface, which led to the formation of protective film on the mild steel surface and then it retarded the extent of the dissolution reaction. The decrease in $C_{\mathrm{dl}}$ was attributed to increase in thickness of electrical double layer. The increase in $R_{\mathrm{ct}}$ value was ascribed to the formation of protective film on the metal/ solution interface. These observations suggested that HSLE functioned by adsorption at metal surface, thereby causing the decrease in $C_{\mathrm{dl}}$ values and increase in $R_{\mathrm{ct}}$ values [37]. Inhibition efficiency of the studied inhibitor increased by increasing inhibitor concentrations, which was due to increase in surface coverage. This layer made a barrier for mass and charge transfer for metal dissolution [38].
Table 2 Electrochemical impedance parameters for mild steel in $1 \mathrm{M} \mathrm{H}_{2} \mathrm{SO}_{4}$ in the absence and presence of HSLE

\begin{tabular}{llccl}
\hline$C_{\mathrm{inh}}\left(\mathrm{mg} \mathrm{l}^{-1}\right)$ & $R_{\mathrm{s}}\left(\Omega \mathrm{cm}^{2}\right)$ & $R_{\mathrm{ct}}\left(\Omega \mathrm{cm}^{2}\right)$ & $C_{\mathrm{dl}}\left(\mathrm{F} \mathrm{cm}^{-2}\right)$ & $\% \mathrm{IE}$ \\
\hline 0 & 2.20 & 3.70 & $2.94 \times 10^{-2}$ & - \\
50 & 2.18 & 18.5 & $1.19 \times 10^{-3}$ & 79.9 \\
100 & 2.50 & 25.2 & $6.15 \times 10^{-4}$ & 85.3 \\
150 & 2.99 & 31.2 & $4.05 \times 10^{-4}$ & 88.1 \\
200 & 2.86 & 33.5 & $3.58 \times 10^{-4}$ & 88.9 \\
250 & 3.40 & 55.8 & $1.32 \times 10^{-4}$ & 93.3 \\
\hline
\end{tabular}

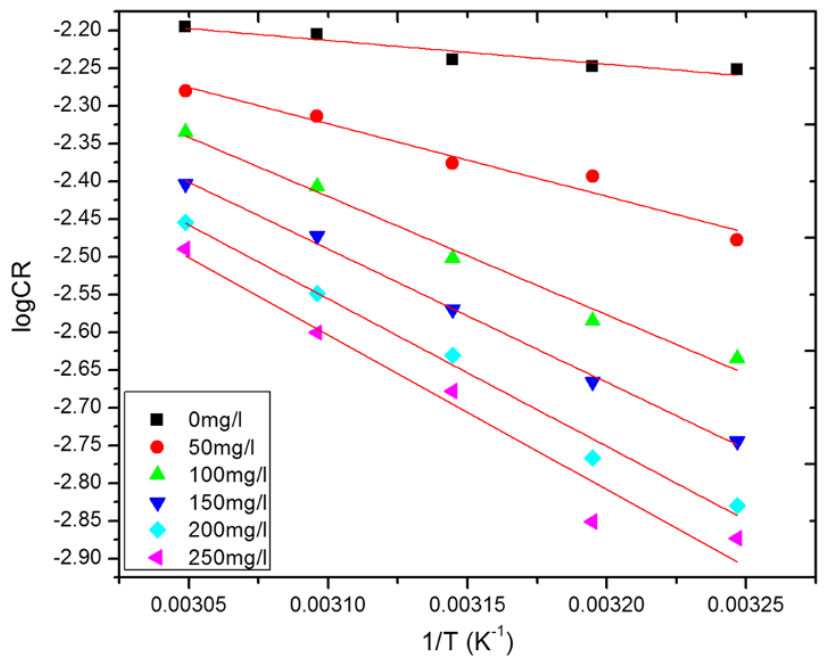

Fig. 7 Arrhenius plots in the absence and presence different concentrations of HSLE

\section{Effect of temperature}

The Arrhenius Eq. (7) and Transition state Eq. (8) were used to calculate the activation parameters for the corrosion process.

$\mathrm{CR}=\mathrm{A} \exp \left(-E_{\mathrm{a}} / R T\right)$

$\mathrm{CR}=R T / h N \exp (\Delta S * / R) \exp (-\Delta H * / R T)$

where $\mathrm{A}$ is the frequency factor, $E_{\mathrm{a}}$ is the activation energy, $R$ is the gas constant $\left(R=8.314 \mathrm{~J} \mathrm{~mol}^{-1} \mathrm{~K}^{-1}\right), T$ is the 


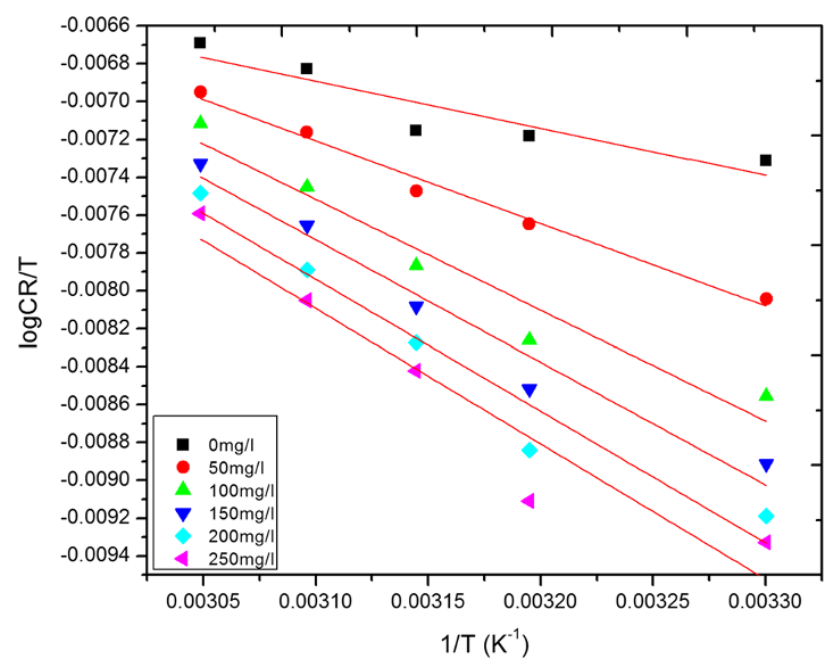

Fig. 8 Transition state plots for mild steel in $1 \mathrm{M} \mathrm{H}_{2} \mathrm{SO}_{4}$ in the absence and presence different concentrations of HSLE

Table 3 Corrosion kinetic parameters for mild steel in $1 \mathrm{M} \mathrm{H}_{2} \mathrm{SO}_{4}$ in the absence and presence of different concentrations of HSLE

\begin{tabular}{llcl}
\hline$C_{\mathrm{inh}}\left(\mathrm{mg} \mathrm{l}^{-1}\right)$ & $E_{\mathrm{a}}\left(\mathrm{kJ} \mathrm{mol}^{-1}\right)$ & $\Delta H^{*}\left(\mathrm{~kJ} \mathrm{~mol}^{-1}\right)$ & $-\Delta S^{*}\left(\mathrm{~J} \mathrm{~mol} \mathrm{k}^{-1}\right)$ \\
\hline 0 & 6.02 & 47.6 & 197.5 \\
50 & 18.4 & 83.5 & 197.4 \\
100 & 30.0 & 112.0 & 197.3 \\
150 & 33.8 & 123.8 & 197.3 \\
200 & 37.4 & 133.2 & 197.3 \\
250 & 39.2 & 136.8 & 197.3 \\
\hline
\end{tabular}

absolute temperature, $h$ is the Planck's constant and $N$ is the Avogadro's number. A plot of log CR vs $1 / \mathrm{T}$ (Fig. 7) and $\log \mathrm{CR} / \mathrm{T}$ vs $1 / \mathrm{T}$ (Fig. 8) gave straight lines with slope of $\left(-E_{\mathrm{a}} / 2.303 \mathrm{R}\right)$ and $\left(-\Delta H^{*} / 2.303 \mathrm{R}\right)$ for Arrhenius and Transition State plots, respectively. The intercept will be A and $\left[\left(\log R / h N+\left(\Delta S^{*} / 2.303 \mathrm{R}\right)\right]\right.$ for Arrhenius and Transition State equations, respectively.

The calculated values of apparent activation energy $\left(E_{\mathrm{a}}\right)$, activation entropies $\left(\Delta S^{*}\right)$ and activation enthalpies $\left(\Delta H^{*}\right)$ are given in Table 3. The values of $E_{\mathrm{a}}$ ranged from 6.02 to $39.2 \mathrm{~kJ} \mathrm{~mol}^{-1}$. That $E_{\mathrm{a}}$ values in the presence of inhibitor are greater than its absence clearly indicated that the corrosion reaction of mild steel was inhibited by HSLE. The increase in the activation energy in the presence of inhibitor signified physical adsorption $[39,40]$. This conclusion was confirmed by the decrease in inhibition efficiency with increasing temperature. The positive values of enthalpies $\left(\Delta H^{*}\right)$, ranged from 47.6 to $136.8 \mathrm{~kJ} \mathrm{~mol}^{-1}$, reflected the endothermic nature of the steel dissolution process suggesting that the dissolution of mild steel was slow in the presence of inhibitor [41]. On comparing the values of entropy of activation $\left(\Delta S^{*}\right)$

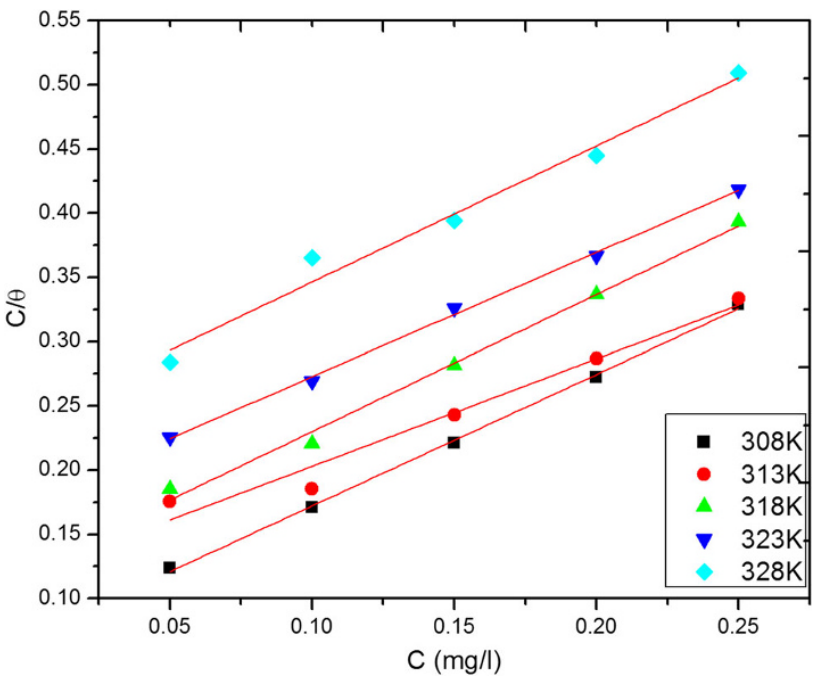

Fig. 9 Langmuir adsorption plots of mild steel immersed in $1 \mathrm{M}$ $\mathrm{H}_{2} \mathrm{SO}_{4}$ with and without HSLE at $308 \mathrm{~K}$

given in Table 3 , it is clear that the entropy of activation increased positively in the presence of plant extract than in its absence. The negative values of entropies $\left(\Delta S^{*}\right)$ implied that the activated complex in the rate determining step represented an association rather than dissociation step meaning that a decrease in disorder took place on going from reactants to the activated complex $[42,43]$.

Adsorption considerations

Adsorption isotherms provide basic information on the interaction between the inhibitor and mild steel surface. The experimental data were applied to various adsorption isotherms including Freundlich, Frumkin, Langmuir, Temkin and Flory-Huggins isotherms. A correlation between surface coverage $(\theta)$ and inhibitor concentration (C) in electrolyte can be represented by the Langmuir adsorption isotherm

$C / \theta=1 / K+C$

where $C$ is the concentration of inhibitor $\left(\mathrm{mg}^{-1}\right), K$ is the adsorption-desorption equilibrium constant and $\theta$ is the surface coverage which is given as

$\theta=\%$ IE $/ 100$

Straight lines were obtained when $C / \theta$ was plotted against $C\left(\mathrm{~g} \mathrm{l}^{-1}\right)$ (Fig. 9). The linear relationships suggested that the adsorption of inhibitors obeyed Langmuir adsorption isotherm. From the intercept of the straight lines, the values of $K$ were calculated and are summarized in Table 4 . The standard free energy of adsorption $\left(\Delta G_{\text {ads }}\right)$ and the equilibrium constant $(K)$ are related by the following equation 
Table 4 Langmuir adsorption parameters and free energy of adsorption of HSLE as an inhibitor on the surface of mild steel

\begin{tabular}{llclll}
\hline $\begin{array}{l}\text { Temp } \\
(K)\end{array}$ & $\begin{array}{l}-\Delta \mathrm{G}_{\mathrm{ads}}^{\circ} \\
\left(\mathrm{kJ} \mathrm{mol}^{-1}\right)\end{array}$ & $K$ & $\begin{array}{l}-\Delta H^{\circ} \text { ads } \\
\left(\mathrm{kJ} \mathrm{mol}^{-1}\right)\end{array}$ & $\begin{array}{l}-\Delta S^{\circ} \text { ads } \\
\left.(\mathrm{J} \mathrm{mol} \mathrm{k})^{-1}\right)\end{array}$ & $R^{2}$ \\
\hline 308 & 17.1 & 14.4 & 48.4 & 101.7 & 0.999 \\
313 & 15.9 & 8.40 & & 103.7 & 0.970 \\
318 & 16.1 & 8.13 & 101.6 & 0.993 \\
323 & 15.4 & 5.68 & 102.2 & 0.998 \\
328 & 14.8 & 4.16 & 102.5 & 0.981 \\
\hline
\end{tabular}

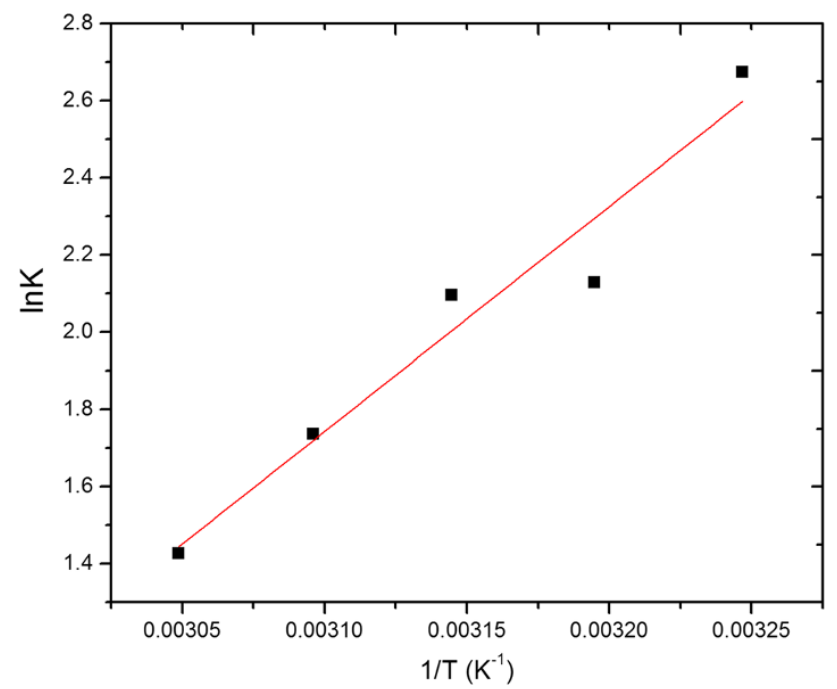

Fig. 10 Plot of $\ln K$ versus $1 / T$ for the adsorption of HSLE at mild steel/sulphuric acid interface

$$
\Delta G_{\mathrm{ads}}=-R T \ln (55.5 \mathrm{~K})
$$

where $R$ is the gas constant, $T$ is the temperature and 55.5 is the molar concentration of water in solution. The values of $K$ were found to decrease with increasing temperature showing that the interactions between the adsorbed molecules and the metal surface are weakened and the inhibitor molecules become easily removable. Such data explain the decrease in the protection efficiency with increasing temperature. The negative values of $\Delta G_{\text {ads }}$ clearly indicated that spontaneous adsorption of HSLE on mild steel surface took place through physical adsorption mechanism. Usually, values of $\Delta G_{\text {ads }}$ up to $-20 \mathrm{~kJ} \mathrm{~mol}^{-1}$ (as obtained in this study) signify physical adsorption, which was consistent with electrostatic interaction between charged molecules and a charged metal [44, 45].

The heat of adsorption and entropy of adsorption are important parameters for understanding adsorption of organic inhibitors at metal/solution interface. The heat of adsorption $\left(\Delta H_{\text {ads }}\right)$ is calculated using the van't Hoff equation: $\ln K=-\Delta H_{\text {ads }} / R T+$ constant

Figure 10 shows the straight lines of plot of $\ln K$ vs $1 /$ $T$ and slope of this straight line is equal to- $\Delta H_{\text {ads }} / R$. The heat of adsorption could be approximately regarded as the standard heat of adsorption $\left(\Delta H_{\mathrm{ads}}\right)$ under experimental conditions. Now standard entropy of adsorption $\left(\Delta S_{\text {ads }}\right)$ is obtained by the thermodynamic basic equation:

$\Delta S_{\text {ads }}=\frac{\Delta H_{\text {ads }-} \Delta G_{\text {ads }}}{T}$

All the calculated thermodynamic parameters are listed in Table 4. It has been found that values of $\Delta H_{\text {ads }}$ are negative, suggesting that the adsorption of inhibitor is an exothermic process, which means that lower inhibition efficiency at high temperature. This indicated the gradual desorption of inhibitors from the surface of mild steel [46]. The values of $\Delta S_{\text {ads }}$ are nearly constant and negative, ranging between -101.6 and $-103.7 \mathrm{~J} \mathrm{k} \mathrm{mol}^{-1}$ at a temperature range $308-328 \mathrm{~K}$. This is expected, since adsorption is an exothermic process and is always accompanied by a decrease of entropy. The decrease in entropy suggested that in the rate determining step there is an association rather than dissociation [46].

Kinetics of mild steel corrosion

The kinetics of the mild steel corrosion in the absence and presence of different concentrations of HSLE in $1 \mathrm{M}$ $\mathrm{H}_{2} \mathrm{SO}_{4}$ was studied at $308 \mathrm{~K}$ by fitting the corrosion data into different rate laws. Correlation coefficients $R^{2}$ were used to determine the best rate law for the corrosion process. The rate laws considered were [41, 47]

Zero order; ML $t=k t$

First order : $\operatorname{lnML} t=-k t+\ln \mathrm{W}_{0}$

Second order : $1 / \mathrm{ML} t=k t+1 / \mathrm{W}_{0}$

where $\mathrm{W}_{0}$ is the initial weight of mild steel, ML $t$ is the mass loss of mild steel at time $t$ and $k$ is the rate constant. From this kinetics, the experimental data were best fitted for zero-order kinetics. The plot of MLt against $t$ was liner (Fig. 11) with good correlation coefficients which confirmed zero-order kinetics for the corrosion of mild steel in $1 \mathrm{M}$ sulphuric acid in the absence and presence of HSLE.

\section{FT-IR studies}

FT-IR spectrum of HSLE is shown in Fig. 12a. Original absorption at $3,429 \mathrm{~cm}^{-1}$ (associated hydroxyl) was overlapped by the strong stretching mode of $\mathrm{N}-\mathrm{H}$. The peak at $1,631 \mathrm{~cm}^{-1}$ indicated the presence of $\mathrm{C}=\mathrm{O}$ stretching mode. The peaks for $\mathrm{C}-\mathrm{H}$ scissoring and bending modes were noticed at 1,396 and $1,287 \mathrm{~cm}^{-1}$, respectively. The 


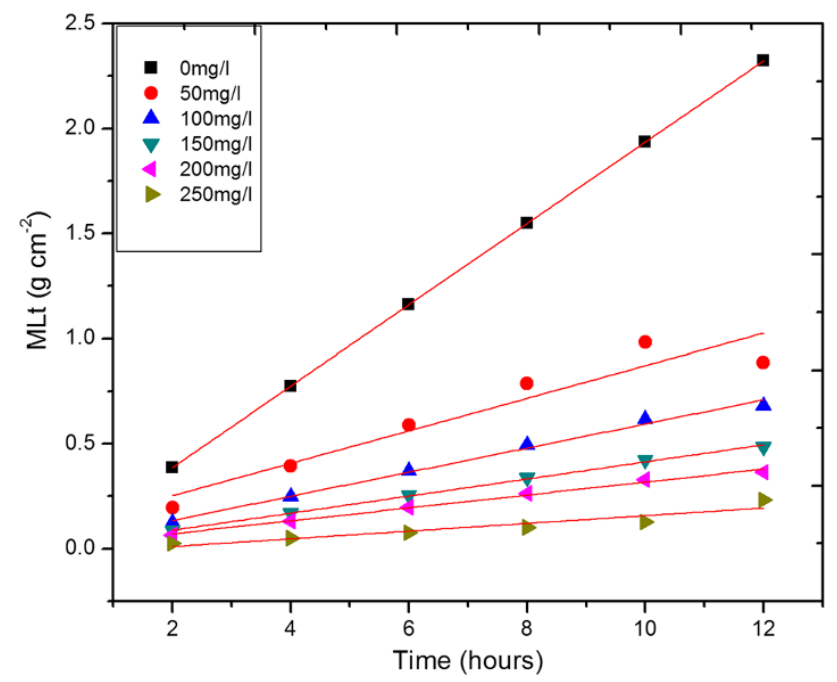

Fig. 11 Plot of MLt versus $T$ for mild steel in $1 \mathrm{M} \mathrm{H}_{2} \mathrm{SO}_{4}$ containing different concentrations of inhibitor

peak at $1,116 \mathrm{~cm}^{-1}$ implied the presence of $\mathrm{C}=\mathrm{O}$ stretching in $\mathrm{C}-\mathrm{O}-\mathrm{C}$. The band at $1,072 \mathrm{~cm}^{-1}$ was due to the stretching mode of $\mathrm{C}-\mathrm{N}$ stretching vibrations. The peak at $609 \mathrm{~cm}^{-1}$ was attributed to the stretching mode of aromatic carboncarbon triple bond. The Fourier transform infrared spectrum of adsorbed protective layer formed on mild steel surface after immersion in $1 \mathrm{M} \mathrm{H}_{2} \mathrm{SO}_{4}$ containing $250 \mathrm{mg} \mathrm{l}^{-1} \mathrm{HSLE}$ is shown in Fig. 12b. On comparing Fig. 12a, b, it could be seen that certain additional peaks had appeared and some had shifted to higher frequency region, providing information that some interaction/adsorption over metal surface had taken place. The absorption bands at 611 and $472 \mathrm{~cm}^{-1}$ were due to $\mathrm{C} \equiv \mathrm{C}$ and $\mathrm{Fe}-\mathrm{N}$ stretching vibration. The above results suggested the presence of inhibitor complex with $\mathrm{Fe}^{2+}$ on the surface [48].

Analysis of the X-ray diffraction patterns

$\mathrm{X}$-ray diffraction studies were used to determine film formation of mild steel in various test solutions. The corrosion product over the surface of the mild steel in sulphuric acid solution is shown in Fig. 13a. The peak at $2 \theta=35.5^{\circ}$, $59.9^{\circ}, 71.7^{\circ}$ suggested the presence iron oxide $\left(\mathrm{Fe}_{2} \mathrm{O}_{3}\right)$ and very small amount of brown film, which led to corrosion. Figure $13 \mathrm{~b}$ shows the X-ray diffraction pattern of mild steel immersed in the test solution containing $250 \mathrm{mg} \mathrm{l}^{-1}$ HSLE. The iron peaks at $2 \theta=44.6^{\circ}$ and $65.5^{\circ}$ in Fig. $13 \mathrm{~b}$ shows the absence of oxides of iron $\left(\mathrm{Fe}_{2} \mathrm{O}_{3}, \mathrm{Fe}_{3} \mathrm{O}_{4}\right.$ and $\mathrm{FeOOH}$ ). The formation of adsorbed protective film on the surface of metal in the presence of HSLE is clearly reflected from these observations $[49,50]$. No brown film was observed.
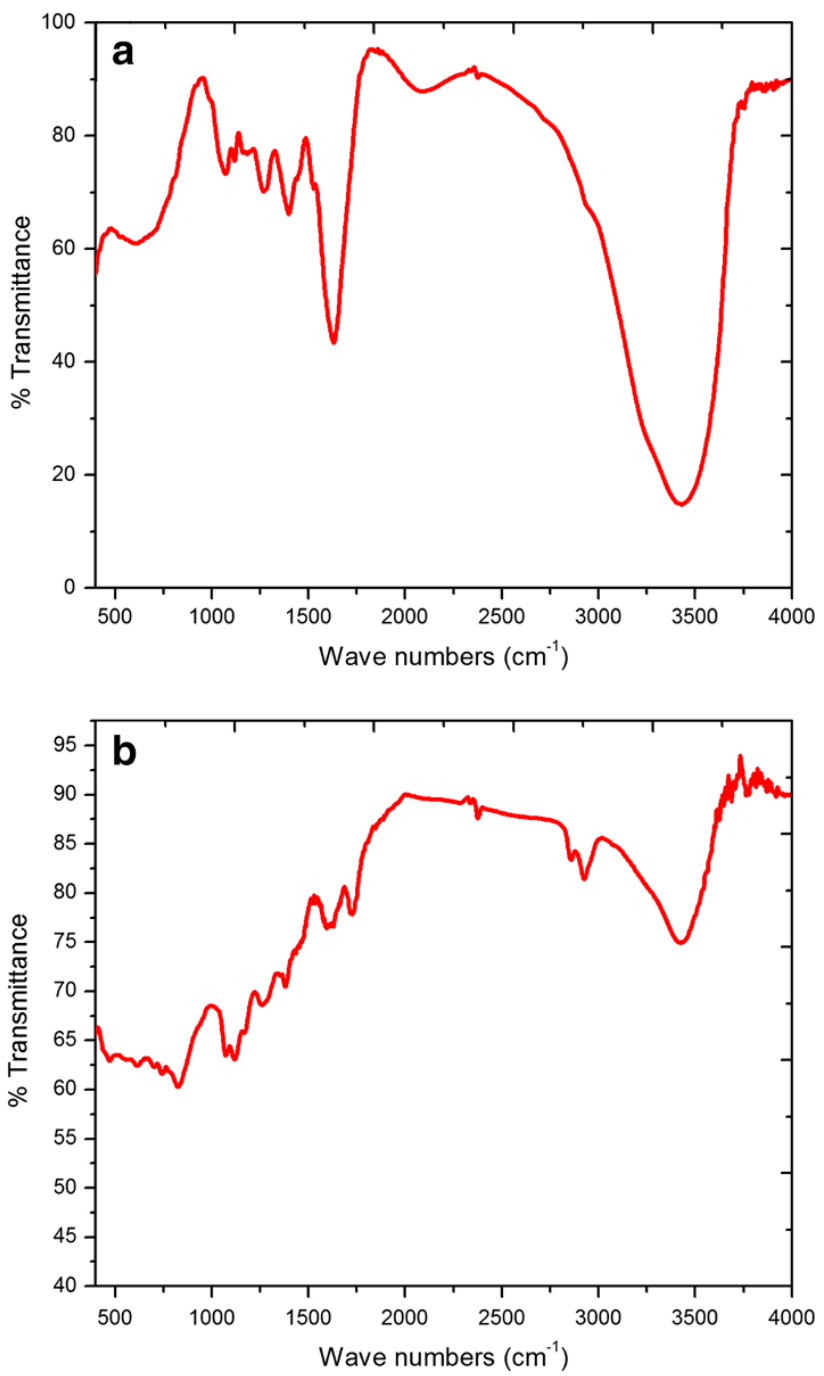

Fig. 12 FT-IR spectra of a Hyptis suaveolens leaf extract $\mathbf{b}$ adsorbed layer formed on the mild steel after immersion in $1 \mathrm{M} \mathrm{H}_{2} \mathrm{SO}_{4}$ containing inhibitors

Scanning electron microscopic studies

Polished mild steel specimens immersed in $1 \mathrm{M} \mathrm{H}_{2} \mathrm{SO}_{4}$ solution in the absence and presence of $250 \mathrm{mg} \mathrm{l}^{-1} \mathrm{HSLE}$ for $12 \mathrm{~h}$ are shown in Fig. 14a, b. It could be observed from Fig. 14a that the surface of the mild steel was strongly damaged in the absence of inhibitors due to metal dissolution in acid solution. The surface was highly porous and the large and deep holes appeared. Figure 14b shows the appearance of smooth mild steel surfaces after the addition of inhibitors to the solution. It could be seen from Fig. 14b that the rate of corrosion reduced and the smooth surfaces appeared by formation of a protective film on the metal surface, which was responsible for the inhibition of corrosion. 


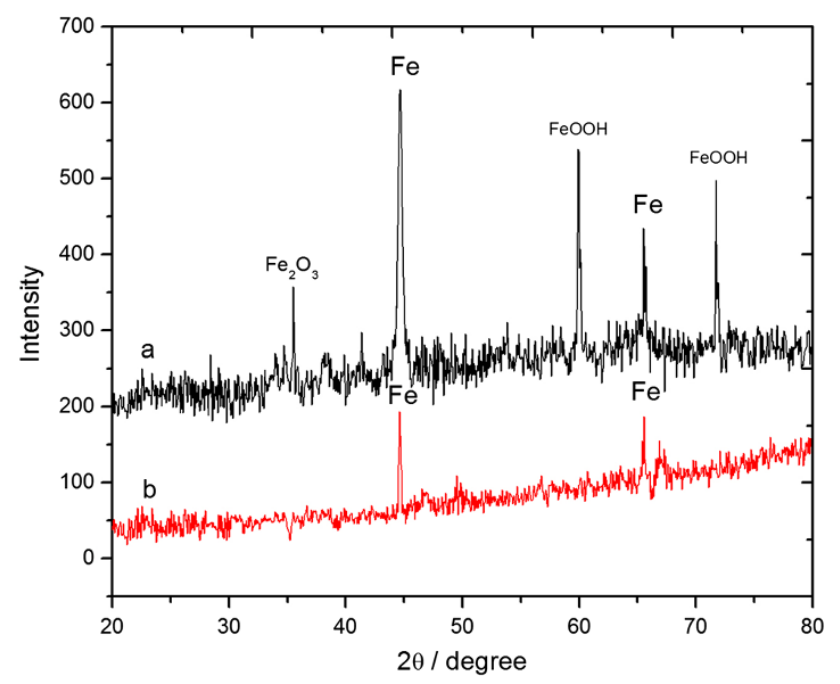

Fig. 13 XRD spectrum of mild steel corrosion in the $a$ absence and $b$ presence of $H S L E$
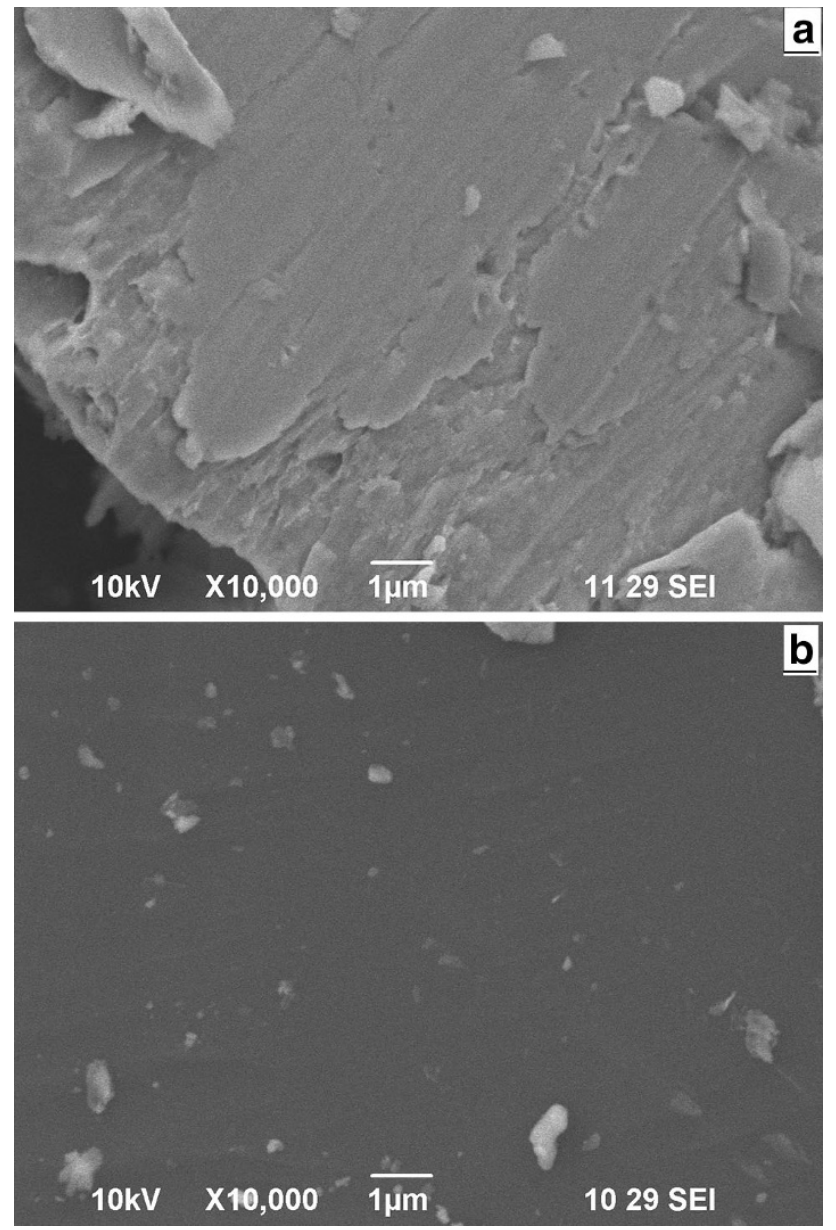

Fig. 14 SEM images of mild steel in $1 \mathrm{M} \mathrm{H}_{2} \mathrm{SO}_{4}$ a without inhibitor and $\mathbf{b}$ with $250 \mathrm{mg}^{-1}$ of inhibitor
Mechanism of inhibition

From the experimental and theoretical results obtained, the inhibition effect of HSLE in $\mathrm{H}_{2} \mathrm{SO}_{4}$ solution can be explained as follows:

HSLE $+\mathrm{xH}^{+} \leftrightarrow[\text { HSLEHx }]^{\mathrm{x}+}$

In aqueous acidic solutions, the HSLE exists either as neutral molecules or in the form of cations (protonated HSLE). Generally, two modes of adsorption could be considered. The neutral HSLE may be adsorbed on the metal surface via the chemisorption mechanism involving the displacement of water molecules from the metal surface and the sharing of electrons between oxygen atom and iron. The HSLE molecules can be adsorbed also on the metal surface based on the donor-acceptor interactions between $\pi$-electrons of the heterocycle and vacant $d$-orbitals of iron. On the other hand, the protonated HSLE may be adsorbed through electrostatic interactions between the positive molecules and already adsorbed sulfate ions. Thus, the metal complexes of $\mathrm{Fe}^{2+}$ and HSLE or protonated HSLE might be formed as follows:

$$
\begin{aligned}
& \mathrm{HSLE}+\mathrm{Fe}^{2+} \leftrightarrow[\mathrm{HSLE}-\mathrm{Fe}]^{2+} \\
& {[\mathrm{HSLEHx}]^{\mathrm{x}+}+\mathrm{Fe}^{2+} \leftrightarrow\left[\mathrm{HSLE}_{\mathrm{x}}-\mathrm{Fe}\right]^{(2+\mathrm{x})+}}
\end{aligned}
$$

These complexes might be adsorbed on mild steel surface in this study by vander Waals force to form a protective film to keep the mild steel surface from corrosion. Similar mechanism has been documented [41, 51].

\section{Conclusion}

Hyptis suaveolens leaf extract acted as a good inhibitor for the corrosion of mild steel in $1 \mathrm{M} \mathrm{H}_{2} \mathrm{SO}_{4}$. Inhibition efficiency values increased with increasing the concentration of HSLE extract but decreased with temperature. Polarization studies showed that HSLE acted as a mixed-type inhibitor by preventing anodic metal dissolution and cathodic hydrogen evolution reaction. AC impedance plots of mild steel showed that charge-transfer resistance increased with increase of HSLE. Adsorption of inhibitor molecules (HSLE) on the mild steel surface was found to obey the Langmuir adsorption isotherm and is a spontaneous, exothermic process accompanied by an increase in entropy. Increase in activation energy of corrosion process in the presence of HSLE indicated physical adsorption. The corrosion of mild steel in $1 \mathrm{M}$ sulphuric acid in the absence and presence of HSLE was found to follow zero-order kinetics. Protective film formation against acid attack was confirmed by FT-IR, XRD and SEM techniques. 
Conflict of interest The authors declare that they have no competing interests.

Authors contribution Muthukrishnan P carried out mass loss measurements, electrochemical measurements, Fourier Transform Infra red spectroscopy, X-ray diffraction studies and scanning electron microscopy. Jeyaprabha B and Prakash P carried out mechanism of corrosion inhibition interpretation of results and drafted the manuscript. All authors read and approved the final manuscript.

Open Access This article is distributed under the terms of the Creative Commons Attribution License which permits any use, distribution, and reproduction in any medium, provided the original author(s) and the source are credited.

\section{References}

1. Doner A, Solmaz R, Ozcan M, Kardas G (2011) Experimental and Theoretical studies of thiazoles as corrosion inhibitors for mild steel in sulphuric acid solution. Corr Sci 53:2902-2913

2. Bouklash M, Hammoutim B, Benkaddour M, Benhadda T (2005) Thiophene derivatives as effective inhibitors for the corrosion of steel in $0.5 \mathrm{M} \mathrm{H}_{2} \mathrm{SO}_{4}$. J Appl Electrochem 35:1095-1101

3. Sorkhabi HA, Seifzadeh D, Hosseini MGEN (2008) EIS and polarization studies to evaluate the inhibition effect of $3 \mathrm{H}$-phenothiazin-3-one,7-dimethylamine on mild steel corrosion in $1 \mathrm{M}$ $\mathrm{HCl}$ solution. Corr Sci 50:3363-3367

4. Quarishi MA, Ansari FA, Jamal D (2002) Thiourea derivatives as corrosion inhibitors for mild steel in formic acid. Mater Chem Phys 77:687-690

5. Hosseni M, Mertens SFL, Ghorbani M, Arshadi AR (2003) Asymmetrical Schiff bases as inhibitors of mild steel corrosion in sulphuric acid media. Mater Chem Phys 78:800-808

6. Emregul KC, Hayvali M (2006) Studies on effect of a newly synthesised Schiff base compound from phenazone and vanillin on the corrosion of steel in $2 \mathrm{M} \mathrm{HCl}$. Corr Sci 48:797-812

7. Popova A, Chirstov M, Zwetanova A (2007) Effect of the molecular structure on the inhibitor properties of azoles on mild steel corrosion in $1 \mathrm{M}$ hydrochloric acid. Corr Sci 49:2131-2143

8. Bahrami MJ, Hosseini SMA, Pilvar P (2010) Experimental and theoretical investigation of organic compounds as inhibitors for mild steel in sulfuric acid medium. Corr Sci 52:2793-2803

9. Sorkhabi HA, Asghari E (2008) Effect of hydrodynamic conditions on the inhibition performance of 1-methionine as a green inhibitor. Electrochim Acta 54:162-167

10. Oguzie EE (2008) Studies on the inhibitive effect of Ocimum viridis extract on the acid corrosion of mild steel. Mater Chem Phys 99:441-446

11. Okafor PC, Ikpi ME, Uwah IE, Ebenso EE, Ekpe UJ, Umoren SA (2008) Inhibitory action of Phyllanthus amarus extracts on the corrosion of mild steel in acidic media. Corr Sci 50:2310-2317

12. Ismail KM (2007) Evaluation of cysteine as environmentally friendly corrosion inhibitor for copper in neutral and acid chloride solutions. Electrochim Acta 52:7811-7819

13. Lebrini M, Robert F, Roos C (2010) Inhibition effect of alkaloids extract from Annona squamosa plant on the corrosion of C38 steel in normal hydrochloric acid medium. Int J Electrochem Sci 5:1698-1712

14. Afia L, Salghi R, Bammou L, Bazzi Lh, Hammouti B, Bazzi L (2012) Application of Argan plant extract as green corrosion inhibitor for steel in $1 \mathrm{~mol} \mathrm{l}^{-1} \mathrm{HCl}$. Acta Metall Sin (Eng Letters) 25:10-18

15. Lahhit N, Bouyanzer A, Desjobert JM, Hammouti B, Salghi R, Costa J, Jama C, Bentiss F, Majidi L (2011) Fennel essential oil as green corrosion inhibitor of carbon steel in hydrochloric acid medium. Portugaliae Electrochimica Acta 29:127-138

16. Vinodkumar KP, Sangaranarayanapillai M, Rexinthusnavis G (2011) Seed extract of Psidium guajava as ecofriendly corrosion inhibitor for carbon steel in hydrochloric acid medium. J Meter Sci Technol 27(12):1143-1149

17. Subramania A, Sathya priya AR, Saravanan S, Abdul Nasser AJ, Vasudevan T (2005) Investigation of some natural product extract as corrosion inhibitors for mild steel in acid medium. Corr Sci Tech 4:231-235

18. Dahmani M, Et-Touhami A, Al-Deyab SS, Hammouti B, Bouyanzer A (2010) Corrosion inhibition of C38 steel in $1 \mathrm{M} \mathrm{HCl}$ : a comparative study of black pepper extract and its isolated piperine. Int J Electrochem Sci 5:1060-1069

19. Behpour M, Ghoreishi SM, Khayatkashani M, Soltani N (2012) Green approach to corrosion inhibition of mild steel in two acid solutions by the extract of Punica granatum peel and main constituents. Mater Chem Phys 131:621-633

20. Moretti G, Guidi F, Grion G (2004) Tryptamine as a green iron corrosion inhibitor in $0.5 \mathrm{M}$ deaerated sulphuric acid. Corr Sci 46:387-403

21. Fallavena T, Antonow M, Goncalves RS (2006) Caffeine as nontoxic corrosion inhibitors for copper in aqueous solutions of potassium nitrate. Appl Surf Sci 253:566-571

22. Bouyanzer A, Hammouti B, Majidi L (2006) Pennyroyal oil from Mentha pulegium as corrosion inhibitor for steel in $1 \mathrm{M} \mathrm{HCl}$. Mater Lett 60:2840-2843

23. Zhang DQ, Cai QR, Gao LX, Lee KY (2008) Effect of serine, threonine and glutamic acid on the corrosion of copper in aerated hydrochloric acid. Corr Sci 50:3615-3621

24. De Souza FS, Spinelli A (2009) Caffeic acid as a green corrosion inhibitor for mild steel. Corr Sci 52:642-649

25. Pachkore GL, Dhale DA, Dharasurkar AN (2011) Antimicrobial and phytochemical screening of Hyptis suaveolens (L. Poit) Lamiaceae. Intern Multidis Res J 1/4:01-03

26. Koche D, Shirsat R, Imran S, Bhadange DG (2010) Phytochemical screening of eight traditionally used ethanomedicinal plants from Akola district (MS) India. Int J Pharm Bio Sci 4(1):B253-B-256

27. Satapathy AK, Gunasekaran G, Sahoo SC, Kumar A, Rodrigues PV (2009) Corrosion inhibition by Justicia gendarussa plant extract in hydrochloric acid solution. Corr Sci 51:2848-2856

28. Anwar Sathiq M, Abdual Nasser AJ, Mohamed Sirajudeen P (2011) Adsorption and corrosion inhibition effect of $N$-(1-Morpholinobenzyl) urea on mild steel in acidic medium. Europ $\mathrm{J}$ Chem 8(2):621-628

29. Solomon MM, Umoren SA, Udosoro II, Udoh AP (2010) Inhibitive and adsorption behavior of carboxymethyl cellulose on mild steel corrosion in sulphuric acid solutions. Corr Sci 52:1317-1325

30. Shriver DF, Atkins PW, Langford CH (1994) Inorganic chemistry, 2nd edn. Oxford University Press, Oxford, pp 238-240

31. Tang Y, Yang X, Yang W, Wan R, Yizhong, Yin X (2010) A preliminary investigation of corrosion inhibition of mild steel in $0.5 \mathrm{M} \mathrm{H}_{2} \mathrm{SO}_{4}$ by 2-amino-5-(n-pyridyl)-1,3,4-thiadiazole: polarization, EIS and molecular dynamics simulations. Corr Sci 52:1801-1808

32. Behpour M, Ghoreish SM, Soltani N, Salavati-Niasari M (2009) The inhibitive effect of some bis- $N, S$-bidentate Schiff bases on corrosion behavior of 304 stainless steel in hydrochloric acid solution. Corr Sci 51:1073-1082

33. Musa AY, Kadhum AAH, Mohamad AB, Takriff MS (2010) Experimental and theoretical study on the inhibition performance of triazole compounds for mild steel corrosion. Corr Sci 52:3331-3340

34. El-Etre AY (2007) Inhibition of acid corrosion of carbon steel using aqueous extract of olive leaves. J Coll Interf Sci 314:578-583 
35. Elyn Amira WAW, Rahim AA, Osman H, Awang K, Bothiraja P (2011) Corrosion inhibition of mild Steel in $1 \mathrm{M} \mathrm{HCl}$ solution by Xylopia Ferruginea leaves from different extract and partitions. Int J Electrochem Sci 6:2998-3016

36. Taleb H, Ibrahim, Mohamed abou Z (2011) Corrosion inhibition of mild steel using Fig leaves extract in hydrochloric acid solution. Int J Electrochem Sci 6:6442-6455

37. Naqvi I, Saleemi AR, Naveed S (2011) Cafixime: a drug as efficient corrosion inhibitors for mild steel in acidic media. Int $\mathrm{J}$ Electrochem Sci 6:146-161

38. Avci G (2008) Corrosion inhibition of indole-3-acetic acid on mild steel in 0.5 M HCl. Coll Surf A 317:730-736

39. Obi-Egbedi NO, Obot IB (2010) Adsorption behavior and corrosion inhibitive potential of xanthenes on mild steel/sulphuric acid interface. Arab J Chem 5:121-133

40. Saratha R, Priya SV, Thilagavathy P (2009) Investigation of Citrus aurantiifolia leaves extract as corrosion inhibitor for mild steel in $1 \mathrm{M} \mathrm{HCl}$. Europ J Chem 6(3):785-789

41. Guan NM, Xueming L, Fei L (2004) Synergistic inhibition between $o$-phenanthroline and chloride ion on cold rolled steel corrosion in phosphoric acid. Mater Chem Phys 86:59-68

42. Fouda AS, Al-Sarawy AA, El-Katori EE (2006) Pyrazolone derivatives as corrosion inhibitors for C-Steel in hydrochloric acid solution. Desalination 201:1-13

43. Boukalah M, Hammouti B, Lagrenee M, Bentiss F (2006) Thermodynamic properties of 2, 5-bis(4-methoxyphenyl)-1,3,4oxadiazole as a corrosion inhibitor for mild steel in normal sulfuric acid medium. Corr Sci 48:2831-2837
44. Gunavathy N, Murugavel SC (2012) Corrosion inhibition studies of mild steel in acid medium using Musa Acuminata fruit peel extract. Europ J Chem 9(1):487-495

45. Eduok UM, Umoren SA, Udoh AP (2012) Synergistic inhibition effect between leaves and stem extract of Sida acuta and iodide ion for mild steel corrosion in $1 \mathrm{M} \mathrm{H}_{2} \mathrm{SO}_{4}$ solutions. Arab J Chem $5: 325-337$

46. Li Xianghong, Deng Shuduan, Hui Fu (2012) Inhibition of the corrosion of steel in $\mathrm{HCl}, \mathrm{H}_{2} \mathrm{SO}_{4}$ solutions by bamboo leaf extract. Corr Sci 62:163-175

47. Ebbing DD, Gammon SD (2005) General chemistry. Houghton Mifflin company, Boston

48. Li Xianghong, Deng Shuduan, Hui Fu, Li Taohong (2009) Adsorption and inhibition effect of 6-benzylaminopurine on cold rolled steel in $1 \mathrm{M} \mathrm{HCl}$. Electrochimi Acta 54:4089-4098

49. Abboudi Y, Hammouti B, Abourrichel A, Ihssanel B, Bennamarl A, Charroufi M, Al-Deyab SS (2012) 2-(O-Hydroxyphenyl) benzimidazole as a new corrosion inhibitor for mild steel in hydrochloric acid solution. Int J Electrochem Sci 7:2543-2551

50. Abboud Y, Hammouti B, Abourriche A, Bennamara A, Hannache $\mathrm{H}$ (2012) 5-Naphthylazo-8-hydroxyquinoline (5NA8HQ) as a novel corrosion inhibitor for mild steel in hydrochloric acid solution. Res Chem Intermed 38:1591-1607

51. Bentiss F, Traisnel M, Lagrenee M (2000) The inhibition action of 3, 6-bis(2-methoxyphenyl)-1,2-dihydro 1,2,4,5-tetrazine on the corrosion of mild steel in acidic media. Corr Sci 42:127-146 